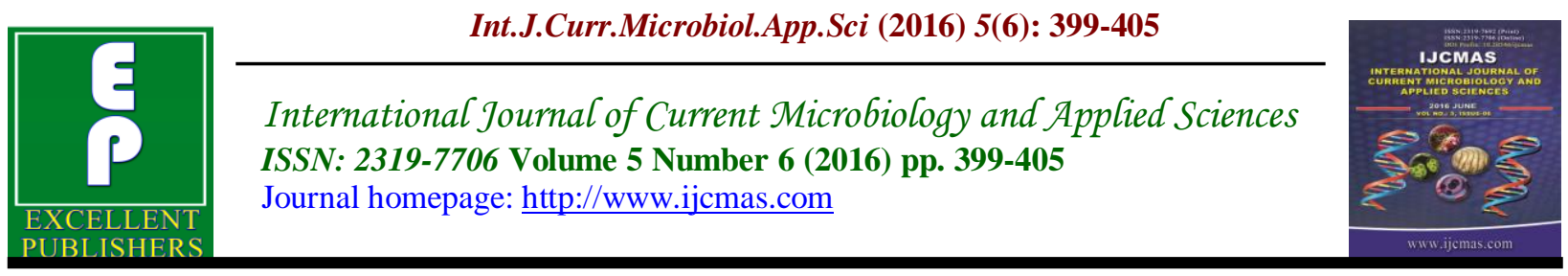

Original Research Article

http://dx.doi.org/10.20546/ijcmas.2016.506.046

\title{
Identification of Polymorphic Microsatellite Markers Linked to Cowpea Resistance to Cowpea Aphid Borne Mosaic Virus (CABMV) in Burkina Faso
}

\author{
Barro Antoine ${ }^{1 *}$, Tignegre Jean Baptiste De La Salle ${ }^{2}$, Kiebre Zakaria ${ }^{1}$, \\ Drabo Issa $^{3}$ and Sawadogo Mahamadou ${ }^{1}$ \\ ${ }^{1}$ Université Ouaga I Professeur Joseph KI-ZERBO (Burkina Faso) \\ ${ }^{2}$ Institut de l'Environnement et de la Recherche Agricole (INERA) CREAF de Kamboinse \\ (Burkina Faso) \\ ${ }^{3}$ Institut de l'Environnement et de la Recherche Agricole (INERA), Saria, (Burkina Faso) \\ *Corresponding author
}

\author{
A B S T R A C T
}

Keywords

Cowpea, microsatellite, CABMV, polymorphism, Burkina Faso.

\section{Article Info}

Accepted: 16 May 2016 Available Online: 10 June 2016
Cowpea is rich in proteins and contains essential amino acids. It is used for nutrition. For the producers, it is an important source of incomes. Cowpea is mainly grown for its grains, its leaves, its young pods. However several viral diseases attack cowpea. The most dangerous one is yellow mosaic transmitted by aphids or Cowpea Aphid Borne Mosaic Virus (CABMV). This disease causes the decrease of crop at a rate of 60 to $90 \%$ and provokes dwarfism, chlorosis of nervures. The identification of polymorphic microsatellite markers linked to cowpea resistance to Cowpea Aphid Borne Mosaic Virus (CABMV) in Burkina Faso will allow to get resistant varieties to this disease. Extracting the genomic DNA of cowpea plants, their PCR amplification and the identification of polymorphic markers through the revelation of the PCR products have been carried out. Wenty seven (27) primers pairs having SSRs polymorphism test have allowed PCR amplification of the target DNA samples. The sizes of the different fragments ranged between 900 and 50 bases pairs (bp). The microsatellite polymorphism test was done with DNA extracted from six lines of cowpea KVx771-10 x IT93K693-2, ITN87-71-21 pl. 12, resistant to CABMV, Diébougou Local, KVx396-4-5-2D, moderately resistant to CABMV, KVx 61-1 and Gorom Local, very sensitive to CABMV. On a total of 27 markers, seventeen (17) markers revealed polymorphisms microsatellite loci between the six lines of cowpea, a polymorphism rate of $62.96 \%$ obtained for these markers. The bands of the same size present in resistant and susceptible varieties could correspond to alleles of the gene conferring susceptibility to CABMV and those of same size present only in resistant varieties would be alleles of the gene conferring resistance to CABMV. The identified polymorphic markers will be used for validation.

\section{Introduction}

Cowpea Aphid-Borne Mosaic Virus (CABMV) is the most damaging and most wide spread virus particularly in Africa (Reeves, 1983). The yield losses of $100 \%$ 
were attributed to this virus in Nigeria (RAHEJA and LELEJI, 1974). Four serotypes of CABMV named C, D, E and F were identified in the three agro-ecological zones of Burkina Faso. The most important is the serotype D (NEYA, 2002). The fight against CABMV must focus on the search of resistant genotypes. Molecular markers appear as a key tool for better identification of the gene of interest into the genome of the resistant varieties. This new approach ensures better description of the genetic variability of plant species and especially to provide solutions to the shortcomings of conventional methods of breeding and varietal improvement. These markers are now becoming an essential tool for improving plants and open new perspectives for breeders (MOREAU et al., 2001 EAGLES et al., 2001). In this study it is the SSRs microsatellite markers that were used for DNA extraction. The study therefore focused on identifying polymorphic markers associated with resistance to cowpea CABMV in the Laboratory of Genetics and Plant Biotechnology Institute of the Environment and Agricultural Research (INERA) in Ouagadougou.

\section{Material and Methods}

\section{Vegetal Material}

On the whole six (6) cowpea lines taken from the conservation of long duration germplasm of INERA / Kamboinsé (Burkina Faso) were used in our study. Among these cowpea lines five come from Burkina Faso and one from Niger. The table below lists the cowpea genotypes used in this study.

\section{Laboratory Equipment}

Besides the vegetal material the study required laboratory equipment - the twentyseven polymorphic microsatellite markers used by Li et al., (2001). They are: VM3, VM5, VM11, VM12, VM13, VM14, VM17, VM19, VM22, VM23, VM25, VM26, VM27, VM28, VM30, VM31, VM33, VM34, VM35, VM36, VM37, VM38, VM39, VM40, VM68, VM70, and VM71.

\section{Extracting of Total DNA}

The total genomic DNA of the six fixed lines of cowpea - KVx771-10 x IT93K6932; ITN87-71-21PL-1-2, Diébougou local, KVx396-4-5-2D, KVx 61-1 and Gorom local (sensitive witness CABMV) were extracted from young leaves freshly picked. For this, we used the method of FTA card extraction of DNA. It is a method which allow us to go faster from the extraction of DNA to PCR. It consist taking the fresh young leaves and crush them on the rough side (square) of the FTA card. The sample are dried in 30 minutes and then disks of 1 $\mathrm{mm}$ diameter are punched which are placed in Eppendorf tubes. To the taken samples $200 \mu \mathrm{l}$ of FTA buffer is added. The whole is incubated at a room temperature during five minutes. This operation is repeated three times by renewing the buffer. At the end, we rinse the disk with $200 \mu$ of TE buffer (10 $\mathrm{mM}$ Tris-HCl, $0.1 \mathrm{mM}$ EDTA, $\mathrm{pH}$ 8.0) and then we dried it five minutes before transferring directly each disk in an Eppendorf tube for polymerase chain reaction (PCR).

\section{PCR Amplification of Genomic DNA}

The DNA amplification has been executed with the thermocycler Eppendorf Master Cycler Gradient in a volume of $25 \mu \mathrm{l}$ containing $5 \mu \mathrm{l}$ of premix (with $1 \mathrm{U}$ of Taq polymerase, $250 \mathrm{mM}$ of dNTPs, $10 \mathrm{mM}$ Tris- $\mathrm{HCl}, 30 \mathrm{mM} \mathrm{KCl}, 1.5 \mathrm{mM} \mathrm{MgCl} 2), 1$ $\mu \mathrm{l}$ of each primer microsatellite $\mathrm{F}$ (Forward) and $\mathrm{R}$ (Reverse) and twenty seven samples (VM3, VM5, VM11, VM12, VM13, VM14, 
VM17, VM19, VM22, VM23, VM25, VM26, VM27, VM28, VM30, VM31, VM33, VM34, VM35, VM36, VM37, VM38, VM39, VM40, VM68, VM70, VM71), $18 \mu$ of ultrapure water and DNA for each sample. A marker of molecular weight of reference of $50 \mathrm{bp}$ (base pairs) and a control without DNA were used. The method was essentially based on the use of the amplification technique by polymerization in chain (PCR). The amplification program includes an initial denaturation phase at $94^{\circ} \mathrm{C}$ for 2 minutes, $94^{\circ} \mathrm{C}$ denaturation for 45 seconds and hybridization at $51{ }^{\circ} \mathrm{C}$ for 45 seconds, followed by 43 cycles each comprising a denaturation step at $94^{\circ} \mathrm{C}$ for 45 seconds, a hybridization step at $51{ }^{\circ} \mathrm{C}$ for 45 seconds and an elongation step at $72{ }^{\circ} \mathrm{C}$ for 1 minute 30 seconds. The amplification products are denatured at $72^{\circ} \mathrm{C}$ for 10 minutes.

\section{Electrophoresis Separation and Visualization of PCR Products}

The PCR products have been separated on an agarose gel at $4 \%$ concentration and containing ethidium bromide (BET) using fluorescent developer. The migration time varied between 1:30 and 2:10 minutes and was performed in TBE $0.5 \mathrm{x}$ under $85 \mathrm{~V}$ or $100 \mathrm{~V}$ and $50 \mathrm{~mA}$ (milliamp). The revelation of the amplification products was performed by ultraviolet (UV) light in a dark room and photographed with a camera brand Canon Power Shot A620, 7.1 Mega Pixels.

\section{Results and Discussion}

Polymorphism Identifications of Loci Through the Use of Microsatellite Markers

The results of the screening with the markers VM3, VM5, VM11, VM12, VM13, VM14, VM17, and VM19 are presented in
Figure 1. All the markers used allowed the amplification of the DNA. The VM3 marker was polymorphic for the couple of lines (ITN87-71-21pl.1-2, Gorom local). The VM5 marker showed polymorphism between the pair of lines (ITN87-71-21 pl.12, KVx61-1), the VM11 marker for the couple of lines (ITN87-71-21pl.1-2, Diébougou local) and VM12 marker for the couple of lines (KVx771-10 x IT93K693-2, KVx 61-1).

VM13 was polymorphic for the couple of lines (KVx771-10 x IT93K693-2, KVx 3964-5-2D), VM14 for the couple of lines (ITN87-71-21pl.1-2, local Gorom). We notice monomorphic bands at 150 base pairs with VM17 among the six cowpea cultivars and VM19 for the couple of lines (ITN8771-21pl.1-2, Gorom local). The results of screening with markers VM22, VM23, VM25, VM26, VM27, VM28, VM30, VM31, and VM33 are presented in Figure 2.

Same size bands are observed in the six cultivars with VM22, VM23. They are called monomorphic bands markers. The VM26 marker showed bands at 100 and 200 base pairs in cowpea lines, VM27 at 150 and 200 base pairs. These two markers are polymorphic bands. On the other hand the VM28 marker showed bands of the same size to 200 base pairs. They are monomorphic bands. With six primer pairs, three markers, VM22 and VM23 VM28 were monomorphic while four pairs of primers VM25, VM26, VM27 were polymorphic. This suggests that there were $50 \%$ of monomorphic and $50 \%$ of polymorphism bands. The results of screening with markers VM34, VM35, VM36, VM37, VM38, VM39, VM40, VM68, and VM70 are presented in Figure 3.

The VM34 marker showed the same size bands at 150 and 250 base pairs for the six 
genotypes of cowpea; VM35 showed the same size bands at 100 base pairs and VM36 the same size bands of 150 base pairs for six genotypes of cowpea. Therefore no polymorphism was revealed.

With VM37, there is no bands in ITN87-71$21 \mathrm{pl} \mathrm{1-2,} \mathrm{in} \mathrm{local} \mathrm{Diébougou} \mathrm{and} \mathrm{in}$ Kvx396-4-5-2D but bands of equal size to 250 base pairs are noted for local cowpea varieties Gorom, KVx61 -1 and KVx771-10 $x$ IT93K693-2. It is a polymorphism of presence and absence of bands. With markers VM38, VM39 and VM40 bands were monomorphic in all genotypes of cowpea 100, 150 and 200 base pairs. These markers are monomorphic. The VM68 and VM70 markers could not reveal bands in the ITN87-71-21pl 1-2 genotype. For the VM68 marker bands are 250 base pairs and for the VM70 marker 250 and 450 base pairs. There is a polymorphism of presence and absence of bands. The screening result with markers VM71 are presented in figure 4.

With the VM71 marker, There are bands located at 150, 200, 900 base pairs. The bands located at 200 base pairs are monomorphic bands. As against the located bands at 100 and 900 base pairs are polymorphic and characteristics of couple of moderately resistant varieties (Diébougou local, KVx396-4-5-2D).
Genotyping: Polymorphism Loci Microsatellite Markers for Resistance to CABMV

Genotyping of six (6) cowpea genotypes or molecular characterization of amplified DNA fragments allowed us to identify seventeen polymorphic microsatellite markers among the twenty-seven, a rate of $62.96 \%$ of polymorphism versus $37.03 \%$ of monomorphism. Thus VM3 markers VM5, VM11, VM12, VM13, VM14, VM19, VM22, VM25, VM26, VM27, VM30, VM31, VM33, VM37, VM68, VM70 were polymorphic in the experimental conditions of Li et al. (2001) modified. The results are in agreement with those of $\mathrm{Li}$ and al. on the number of bands observed by amplifying of all primer pairs used because their study did not examine the CABMV. The results are explained by the factors influencing the PCR amplification. The analysis of DNA fragments amplified by some primers pairs of microsatellite VM26, VM27, VM28, VM34, VM35, VM36 showed the presence of two bands of different size at the genetic profiles of cultivars. The existence of these two bands or fragments indicates the presence of two amplification products whose sequences have been recognized by the primers used. Both products which could correspond to two alleles of the gene conferring susceptibility to CABMV.

Table.1 List of cowpea genotypes used in this study

\begin{tabular}{|l|l|l|l|}
\hline Number & Lines & Statut relative to CABMV & Origin \\
\hline 1 & Kvx 771-10 x IT93K-693-2 & Resistant & Burkina Faso \\
\hline 2 & ITN87-71-21 pl. 1-2 & Resistant & Niger \\
\hline 3 & Diébougou local & Moderately resistant & Burkina Faso \\
\hline 4 & Kvx396-4-5-2D & Moderately resistant & Burkina Faso \\
\hline 5 & Kvx61-1 & Susceptible & Burkina Faso \\
\hline
\end{tabular}


Fig.1 PCR products Profiles of six cowpea cultivars (1-6 in Table 1) with primers microsatellites VM3-VM5-VM11-VM12-VM13-VM14-VM17-VM19; M: Marker 50 base pairs (bp); C:

Control without DNA
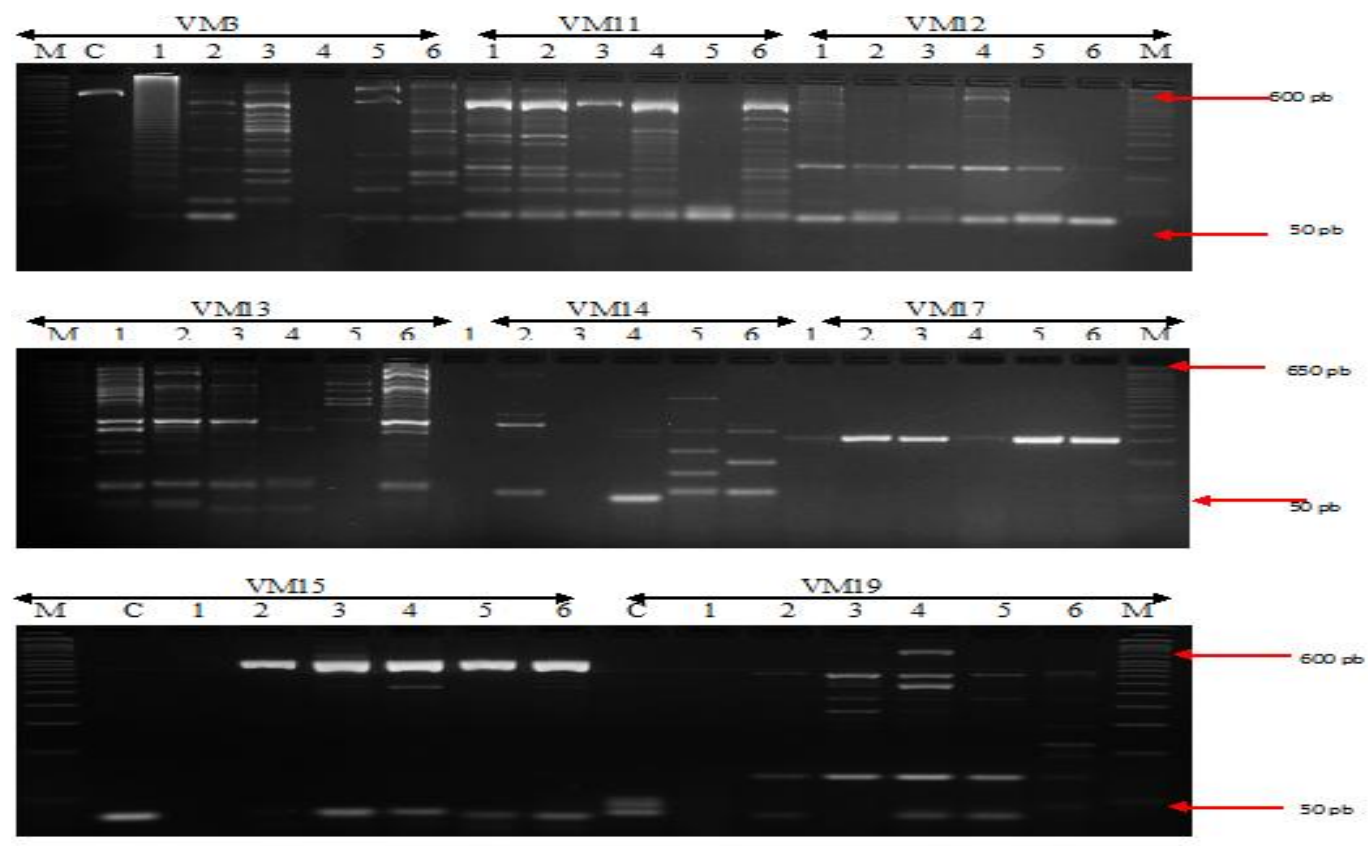

Fig.2 PCR products Profiles of six cowpea cultivars (1-6 in Table 1) with primers microsatellites VM22-VM23-VM25-VM26-VM27-VM28-VM30-VM31-VM33; M: Marker 50 base pairs (bp); C: Control without DNA
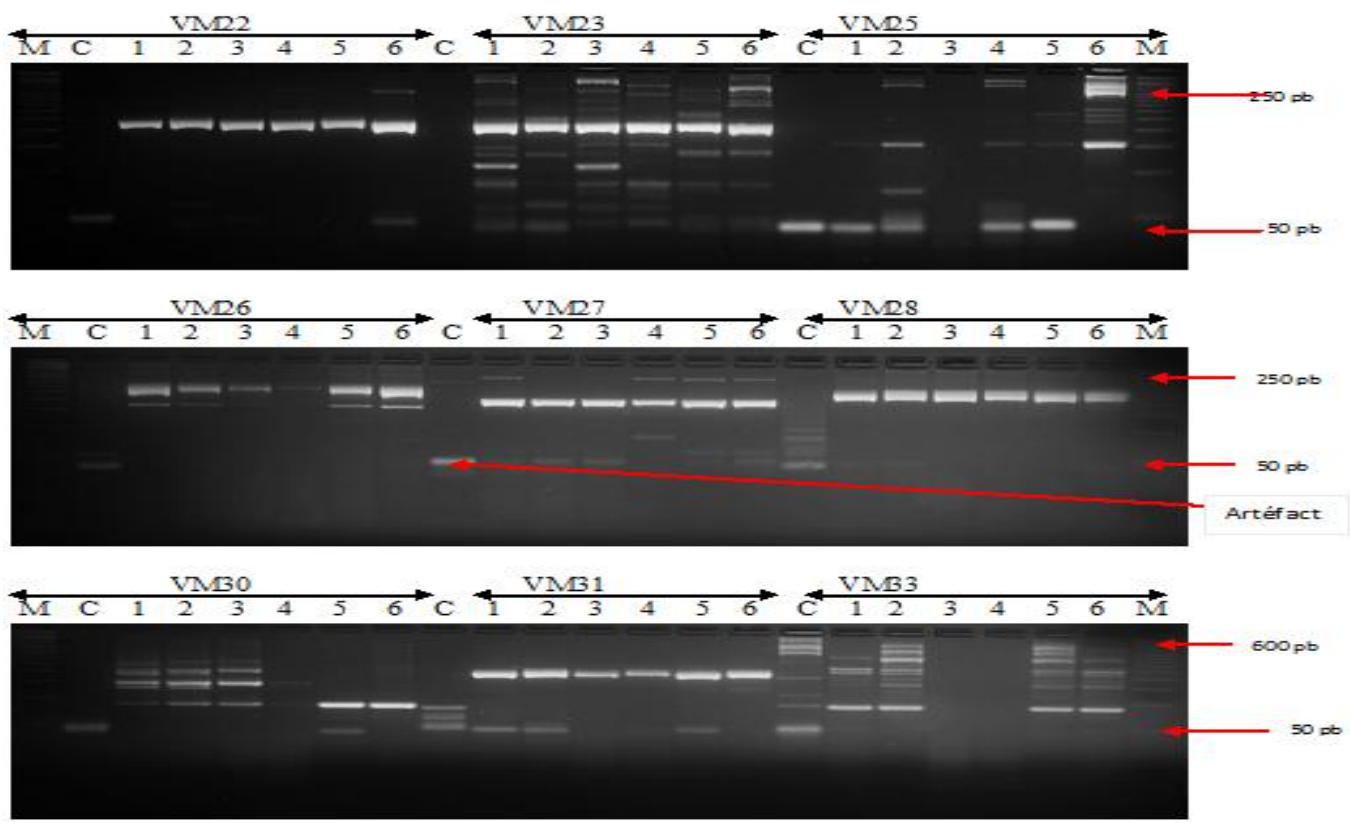
Fig.3 PCR products Profiles of six cowpea cultivars (1-6 in Table 1) with primers microsatellites VM34-VM35-VM36-VM37-VM38-VM39-VM40-VM68-VM70; M: Marker 50 base pairs (bp); C: Control without DNA
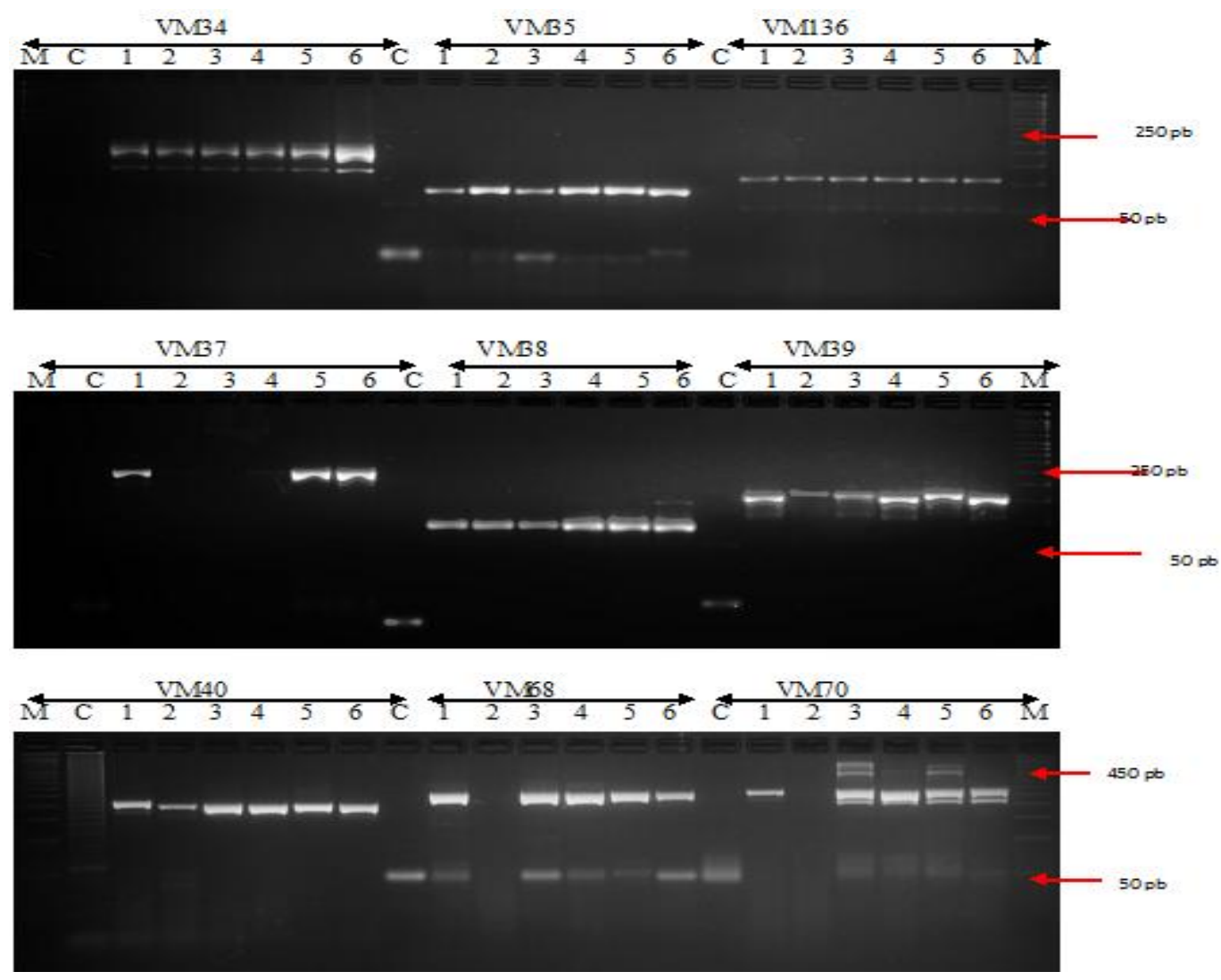

Fig.4 PCR products Profiles of six cowpea cultivars (1-6 in Table 1) with primers microsatellites VM71; M: Marker 50 base pairs (bp); C: Control without DNA

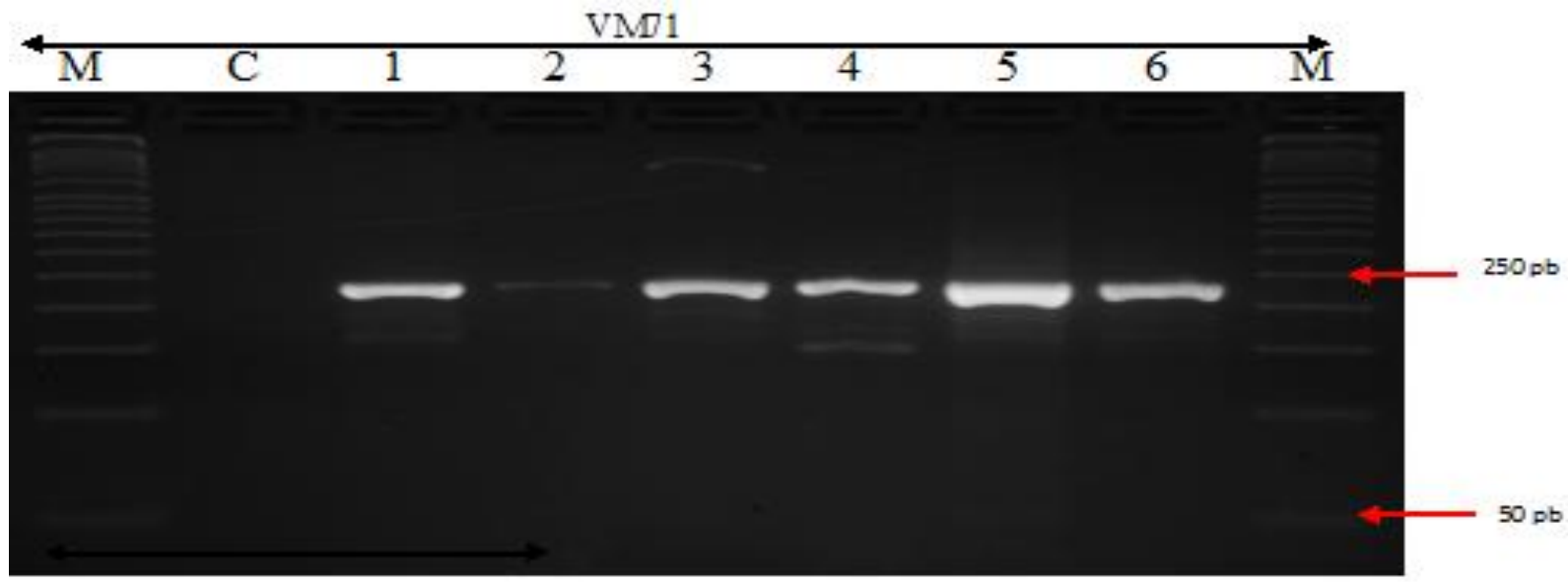

In the control sensitive Gorom local, the same bands are also found in the other five cultivars that are not all susceptible. These markers are called monomorphic. Again, at Figure 1, we notice the presence of a band with the VM13 marker in KVx771-10 $\mathrm{x}$ 
IT93K693-2 which is the resistant variety. This allele may be linked to the resistance gene CABMV. While there has been a polymorphism between the resistant parent (KVx771-10 x IT93K693-2) and sensitive (Gorom local) for primers pairs VM22, VM25, VM5, VM19, VM13, VM14, VM12, VM30, and VM31. Therefore the identified polymorphic markers will be potential candidates for validation.

In conclusion, the objective of this study is to identify polymorphic microsatellite markers associated with resistance to cowpea CABMV. The markers used have been able to detect a repeat polymorphism of DNA fragments. Thus, the molecular study identified seventeen polymorphic markers on twenty seven microsatellite markers; a rate of $62.96 \%$ of polymorphism versus $37.03 \%$ monomorphism. It also allowed detecting bands in relation to the resistant or sensitive phenotypes of cowpea varieties. Indeed, the cowpea line KVx771$10 \times$ IT93K693-2 is the one that did not present band with the primer pairs microsatellites VM5 and VM19. The continuation of our work will consist to validate the identified polymorphic markers. The same validated markers will be used in assisted selection by markers for the search of resistant genotypes to CABMV. Future work should be carry out to know the genetic control of the resistance in order to create CABMV resistant varieties that transmit little or no CABMV.

\section{References}

Eagles, H.A., Bariana, H.S., Ogbonnaya, F.C., Rebetzke, G.J., Hollamby, G.J., Henry, R.J., Henschke, P.H., Carter, M. 2001. Implementation of markers in Australian wheat breeding. Aust. J. Agric. Res., 52(11-12): p. 13491356.

Li, C.D., Fatokun, C.A., Ubi, B., Singh, B.B., G.J. Scoles. 2001. Determining Genetic Similarities and Relationships among Cowpea Breeding Lines and Cultivars by Microsatellites Markers. Crop Sci., 41: 189-197.

Moreau, L., Charcosset, A., Gallais, A. 2001. Efficiency of marker-assisted selection compared with conventional selection. OCL-Ol. Corps Gras Lipides, 8(5): p. 496501.

Neya, J. 2002. Variabilité sérologique et aspects épidémiologiques du virus de la mosaïque du niébé (L.)WALP.) Transmis par pucerons au Burkina Faso. Mémoire de DEA., Université de Ouagadougou, 54p

Raheja, A.K., Leleji, O.I. 1974. An aphidborne virus disease of irrigated cowpea in northern Nigeria. Plant Dis. Reptr., 58: 1080-1084.

Reeves, W.H. 1983. The cowpea. International Institute of Tropical Agriculture. Ibadan Nigeria, 170p.

\section{How to cite this article:}

Barro Antoine, Tignegre Jean Baptiste De La Salle, Kiebre Zakaria, Drabo Issa and Sawadogo Mahamadou. 2016. Identification of Polymorphic Microsatellite Markers Linked to Cowpea Resistance to Cowpea Aphid Borne Mosaic Virus (CABMV) in Burkina Faso. Int.J.Curr.Microbiol.App.Sci. 5(6): 399-405. doi: http://dx.doi.org/10.20546/ijcmas.2016.506.046 